Recibido: 24/02/2020 --- Aceptado: 17/12/2020 --- Publicado: 12/04/2021

\title{
DIALÉCTICA ILUSTRACIÓN Y ROMANTICISMO EN LOS ARTÍCULOS PERIODÍSTICOS DE EL ROBINSON URBANO, DE ANTONIO MUÑOZ MOLINA
}

\section{ENLIGHTENMENT AND ROMANTICISM DIALECTICS IN EL ROBINSON URBANO'S ANTONIO MUÑOZ MOLINA JOURNALISTIC ARTICLES}

Manuel Ruiz Rico. Universidad de Sevilla. España. manuel.ruiz@democmedia.com

Cómo citar el artículo:

Ruiz Rico, M. (2021). Dialéctica Ilustración y Romanticismo en los artículos periodísticos de El Robinson urbano, de Antonio Muñoz Molina. Revista de Comunicación de la SEECI, 54, 55-78. https://doi.org/10.15198/seeci.2021.54.e632

\section{RESUMEN}

El Robinson urbano apareció en 1984 y es la primera obra publicada por Antonio Muñoz Molina. En tanto que opera prima, contiene los elementos clave de la obra inicial del autor jiennense, que harán de cimiento a su producción posterior. Metodología: En este trabajo se analiza dicho título bajo la dialéctica entre la Ilustración y el Romanticismo, que ofrece una óptica desde la que leer los años y las tensiones de la Transición democrática española como período histórico, así como las relaciones entre el periodismo (ejercido en libertad de nuevo) y la literatura. Para hacer este análisis, se emplea bibliografía, por un lado, sobre el periodismo y la literatura y, por otro, sobre la Ilustración y el Romanticismo, así como sobre la Posmodernidad como etapa posromántica. Discusión: El Robinson urbano se presenta, en los primeros años de la democracia española, como una defensa de la razón y del proyecto ilustrado, aunque también es una denuncia de sus riesgos y excesos. Entre ellos, el control social por el Estado, el mercado o la tecnología, la devastación de patrimonio histórico de las ciudades, la alienación del individuo, el regreso de las supersticiones y del folklorismo nacionalista, el esnobismo intelectual o la hegemonía de la moral productivista. Conclusión: Todos ellos son elementos propios de la crítica romántica a la Ilustración, que encuentran en las páginas de un periódico local progresista, en la Granada de la Transición y en la pluma de Muñoz Molina un marco de manifestación y expresión genuino y singular.

PALABRAS ClAVE: Periodismo literario - articulismo - Ilustración - Romanticismo - Transición española - Antonio Muñoz Molina. 


\section{ABSTRACT}

Introduction: The Urban Robinson appeared in 1984. It was the first work published by Antonio Muñoz Molina. As such, it contains the key elements of the initial work of the author. Those elements are foundation for his later production. Methodology: This work analyses The Urban Robinson under the dialectic between the Enlightenment and Romanticism, which offers a perspective from which to read the years and tensions of the Spanish democratic transition as a historical period, as well as the relations between journalism (exercised in freedom again) and literature. To make this analysis, this article uses bibliography on journalism and literature, on the one hand, and, on the other, on Enlightenment and Romanticism, as well as on Postmodernism as a post-Romantic period. Discussion: The Urban Robinson is presented, in the first years of Spanish democracy, as a defence of reason and of the Enlightenment project, although it also reports its risks and excesses. Among them, the social control by the State, the market or technology, the devastation of the historical heritage of the cities, the alienation of the individual, the return of superstitions and nationalist folk/orism, intellectual snobbery or the hegemony of the productivist morality. Conclusion: All these are elements typical of the romantic criticism of the Enlightenment, which find in the pages of a local progressive newspaper, in the Granada of the Transition and in Muñoz Molina's pen, a framework of genuine and singular manifestation and expression.

KEY WORDS: Literary Journalism - column - Enlightenment - Romanticism Spanish Transition - Antonio Muñoz Molina.

\section{DIALÉTICA ILUSTRAÇÃO E ROMANTISMO NOS ARTIGOS PERIODÍSTICOS DO EL ROBINSON URBANO, DE ANTONIO MUÑOZ MOLINA}

\section{RESUMO:}

El Robinson urbano apareceu em 1984 e é a primeira obra publicada por Antonio Muñoz Molina. Enquanto opera prima, contém os elementos chave da obra inicial do autor de jaén (espanha), que será a base da sua produção posterior. Metodología: Neste trabalho se analisa este trabalho usando a dialética entre a Ilustração e o Romantismo, que oferece uma ótica onde se permite ler os anos e as tensões da Transição democrática espanhola como período histórico, assim como as relações entre o jornalismo (exercido em libertad de novo) e a literatura. Para fazer esta análise, foi usado bibliografía, por um lado, sobre o jornalismo e a literatura e, pelo outro, sobre a Ilustração e o Romantismo, assim como sobre a Pós Modernidade como etapa pós romântica. Discussão: El Robinson urbano se apresenta, nos primeiros anos da democracia espanhola, como uma defesa da razão e do projeto ilustrado, porém também é uma denúncia dos seus riscos e excessos. Dentro deles, o controle social pelo Estado, o mercado ou a tecnología, a devastação de patrimônio histórico das cidades, a alienação do indivíduo, o retorno das superstições e do 
folclore nacionalista, o esnobismo intelectual ou a hegemonía da moral produtivista. Conclusão: Todos eles são elementos próprios da crítica romântica à ilustração, que encontram nas páginas de um jornal local progressista, na granada da transição e na caneta de Muñoz Molina um marco de manifestação e expressão genuíno e singular.

PALAVRAS CHAVE: Jornalismo literário; Articulismo; Ilustração; Romantismo; Transição Espanhola; Antonio Muñoz Molina.

\section{INTRODUCCIÓN}

La colección de artículos El Robinson urbano, de Antonio Muñoz Molina, fue publicada por primera vez en 1984 en Granada por la editorial Selene en una autoedición de su autor, quien en ese momento ejercía de funcionario de la Delegación de Cultura del Ayuntamiento de dicha ciudad. Fue ésa la primera obra publicada por el escritor de Ubeda, a la postre, una de las voces más destacadas de la generación que surge inmediatamente después de la Transición (entendiendo ésta como período comprendido entre 1975 y 1982) y, en de las letras españolas de finales del siglo XX y principios del XXI.

Los artículos recogidos en dicho volumen de El Robinson urbano habían sido publicados, salvo dos excepciones ${ }^{1}$, entre el viernes 7 de mayo de 1982 (el segundo número que el periódico ponía en la calle) y el viernes 8 de abril de 1983 en el Diario de Granada y bajo ese mismo epígrafe: El Robinson urbano. Dicho periódico fue un rotativo de nueva creación y de ideología progresista ${ }^{2}$ que apareció en la ciudad en plena Transición. En total, fueron 41 los artículos publicados bajo ese epígrafe en el periódico local granadino.

De una manera más o menos casual, como él mismo ha explicado (Muñoz Molina, 2011), el autor comenzó a publicar sus artículos robinsonianos una vez a la semana (en general, todos los viernes). Aún era un escritor inédito: por aquellos años trabajaba en el borrador de la que después sería su primera novela, Beatus Ille.

El libro recopilatorio de Selene de 1984 sería más tarde reeditado por Seix Barral tras una visita a la ciudad de Pere Gimferrer. Dicho sello editorial permitió al autor ampliar el marco de difusión de lo puramente local a una escala ya nacional. Seix Barral publicó después Beatus I/le, título que dio comienzo a la trayectoria novelística del autor.

\footnotetext{
${ }^{1}$ Un último artículo suyo publicado el sábado 2 de julio de 1983 en Diario de Granada, "Saluda a Alejandría que se aleja", fue incluido en el libro a pesar de no haber aparecido bajo el epígrafe El Robinson urbano. Con todo, Muñoz Molina lo integró en la colección de Selene junto a "Todos los fuegos el fuego", que el escritor había publicado también en ese período de tiempo en la revista Olvidos de Granada.

${ }^{2}$ Su primer director y quien le dio la oportunidad de escribir a Muñoz Molina en el rotativo, Antonio Ramos Espejo, cuenta (Ruiz Rico, 2012, pp. 580-581): "Casi un siglo después nos sentíamos herederos del Defensor de Granada, fundado por Luis Seco de Lucena en junio 1880 (nosotros salimos en mayo de 1982). El Defensor acabó incautado a comienzos de 1936 y su entonces director, Constantino Ruiz Carnero, fusilado, lo mismo que su amigo Federico García Lorca".
}

Revista de Comunicación de la SEECI. 2021, nº 54, 55-78 
Pero Muñoz Molina no sólo publicó artículos durante su colaboración con Diario de Granada sino también noticias, entrevistas, reportajes, crítica literaria, etcétera ${ }^{3}$, forjando así una fructífera colaboración periodística durante esos dos años, 1982 y 1983. Lo primero que publicó, además, no fue una columna de El Robinson urbano sino un artículo de temática y actualidad locales. Esto sucedió el día en que el periódico inició su andadura, el 6 de mayo de 1982. El artículo se tituló "Los carteles del Corpus: persistencia en el error" y lo firmó bajo el seudónimo de Alberto Neira: "Me preocupaba el sonido vulgar de mi nombre, que no me parecía literario", ha explicado el autor (Ruiz Rico, 2012, p. 515).

Finalmente, la firma, el nombre de Antonio Muñoz Molina, nace para las letras españolas al día siguiente, en las páginas de un periódico, con el primer artículo de la serie de El Robinson urbano, en el segundo número de Diario de Granada, un rotativo de ideología progresista que había nacido para la nueva Granada de la democracia recuperada en aquellos años de la Transición española.

El artículo apareció en la página 11 y llevó por título "Primer manual" (en la edición posterior en formato libro, Muñoz Molina cambiaría el título por "Escuela de robinsones", en clara alusión al título de la novela homónima de Julio Verne). Esta columna supone, por lo tanto, el bautismo periodístico y literario de Antonio Muñoz Molina, y lo hace en los últimos coletazos de la Transición española (aún no se había aprobado siquiera el Estatuto de Autonomía de Andalucía ni esta comunidad había celebrado siquiera sus primeras elecciones regionales) y en la ciudad donde la represión franquista había alcanzado una de sus máximas simbologías con el asesinato en los primeros meses de la Guerra Civil de Federico García Lorca.

Muñoz Molina puede considerarse, de este modo, uno de los primeros nombres que surge de la generación literaria de la posTransición, es decir, de la literatura española de la democracia. Muñoz Molina se engarza en la generación justo anterior, esa nueva tanda de autores que había conectado con un nuevo público en una primera etapa de apertura, democracia y libertad desconocida desde hacía cuatro décadas. José Carlos Mainer (2009, p. 68) ha trazado un sucinto recorrido por los nombres que la componen comenzando en 1975 con la publicación de La verdad sobre el caso Savolta, con la que Eduardo Mendoza (nacido en 1943) abre "la nueva narrativa de acción y fantasía". Juan José Millás (1946) "escribió el primer relato que reflejaba los vacíos morales de la nueva época" en Visión del ahogado (1977); José María Guelbenzu (1944) dio forma en El río de la luna (1981) "a la quiebra de ideales posterior a 1968; Luis Mateo Díez (1942) creó un nuevo costumbrismo provinciano en Las estaciones provinciales (1982); José María Merino (1940) "dio mayoría de edad a las novelas de crisis de identidad" con La orilla oscura (1985); Javier Marías (1951) "reinventó una novela psicológica (arbitraria, light, irónica y a la vez inquietante) en El hombre sentimental". La novela de Marías es ya de 1986,

${ }^{3}$ La obra periodística completa de estos dos primeros años en Granada ha sido recogida en la tesis doctoral El Robinson urbano. Soporte periodístico y literario en la obra de Antonio Muñoz Molina (Ruiz Rico, 2012).

Revista de Comunicación de la SEECI. 2021, nº 54, 55-78 
precisamente el año en que Muñoz Molina debuta en la novela con Beatus IIle. El autor de Úbeda entra, por lo tanto, a la historia de la literatura española por la misma puerta que había abierto la generación inmediatamente anterior.

Desde la publicación de su primer título, El Robinson urbano, y de su primera novela, Beatus IIle, una constante va a recorrer la obra de Muñoz Molina: a lo largo de todos estos años, irá publicando con la misma dedicación novelas, ensayos y artículos, todo como parte de la misma obra literaria, como él mismo ha manifestado (en Ruiz Rico, 2012, p. 153):

Una serie de artículos tiene una doble vida: la primera, en el momento de su publicación inmediata, y la segunda ya filtrada por el tiempo, cuando pierde la condición de novedad y puede revelar o no su capacidad de durar. Seleccionar con cuidado los artículos que uno considera que vale la pena reunir en un libro es una tarea literaria, aunque sean libros que no atraen a demasiada gente. [...] Yo no considero ni mucho menos que todos los míos pasen la prueba del tiempo. Pero, en el conjunto de mis libros, creo que los volúmenes de artículos son tan representativos de lo que yo soy y de mi trabajo como las novelas.

La originalidad de este trabajo viene dada, en parte, por el contexto mismo en el que surge la voz de Muñoz Molina como escritor; un contexto dual: el histórico, por un lado (a saber: la Granada de la Transición española), y, por otro, el de tipo material, es decir, las páginas de un periódico (que además es de nueva aparición, precisamente porque vuelve a haber libertad y democracia en España tras el fin del Franquismo).

El estudio de los artículos de El Robinson urbano pretende ser una aportación al estudio de esta generación de escritores de la literatura española (generación que surge, en un momento histórico muy concreto y definitorio) pero también una base desde la que abordar las relaciones entre el periodismo y la literatura. Pero, y esto es acaso lo más decisivo, el estudio de los artículos de El Robinson ofrecerá un análisis de las primeras claves sobre las que surgirá y se asentará la obra posterior de quien es uno de los escritores más destacados de la actual literatura española. Todo ello, además, en una obra escasamente estudiada del autor jiennense. La primera tesis doctoral sobre este título fue defendida en 2012 en la Universidad de Sevilla y apenas hay estudios ${ }^{4}$ sobre la misma a pesar, como defendemos, de su ya señalada triple importancia.

Finalmente, dentro de los diversos enfoques que podrían aplicarse al estudio de $E /$ Robinson urbano, se empleará en este artículo la dialéctica entre la Ilustración y el Romanticismo que late tanto en el interior de estos artículos como, acaso por eso mismo y como se explicará más adelante, en la propia etapa histórica de la Transición y la inmediata posTransición (a partir, como decimos, de 1982). Se trata,

\footnotetext{
${ }^{4}$ Previamente a la tesis doctoral, se publicó (Ruiz Rico, 2011) un libro que analizaba ciertos aspectos de El Robinson urbano. Como consecuencia de dicha tesis doctoral, se publicó (Ruiz Rico, 2013) en la revista Ámbitos un artículo centrado, en este caso, en este título de Muñoz Molina como ejemplo de periodismo literario en la Transición española.
}

Revista de Comunicación de la SEECI. 2021, nº 54, 55-78 
además, de una dialéctica que hace surgir otras de carácter interno y que vertebran la obra, a saber: ciudad-campo, noche-día, libertad-dictadura, Robinson-Apolodoro, mito-realidad, poesía-prosa, mirar-escribir, interior-exterior, lo femenino y lo masculino, periodismo-literatura, pensar-actuar, viaje interior-viaje exterior, etcétera.

Es éste un enfoque también novedoso en el estudio de la obra de Muñoz Molina. El empleo de este prisma arrojará resultados que no sólo buscan pasar a formar parte del corpus de artículos, ensayos y libros sobre la obra del autor sino que podrían aportar a su vez una mirada diferente y una luz nueva y genuina sobre otros títulos del autor de El jinete polaco, de manera que se abra, de este modo, una nueva vía para futuras investigaciones.

\section{OBJETIVOS}

Este trabajo parte con el objetivo principal de resaltar la importancia de la dialéctica entre la Ilustración y el Romanticismo en la opera prima de Antonio Muñoz Molina. Se trata El Robinson urbano de una de las obras menos estudiadas del autor. Por otra parte, la obra del escritor de úbeda se ha analizado desde multitud de puntos de vista y enfoques, sin embargo, las tensiones entre ambas corrientes culturales es una aportación que consideramos nueva y que aporta resultados muy enriquecedores en la investigación y consideración del universo periodístico y literario de Muñoz Molina.

\section{METOdOLOGÍA}

En esta investigación se ha usado una amplia bibliografía sobre los dos grandes temas sobre los que transita, a saber: la Ilustración y el Romanticismo. Asimismo, se ha empleado para el análisis los artículos originales publicados por Muñoz Molina en Diario de Granada en 1982 y 1983 bajo el epígrafe El Robinson urbano. La colección de artículos publicada por el propio autor en Granada un año más tarde, en 1984, recoge una selección (no la totalidad) de los mismos con ciertas modificaciones (sobre todo de los aspectos más locales y de actualidad de la ciudad misma) y correcciones.

\section{DISCUSIÓN}

\subsection{La Ilustración y el concepto de progreso en las sociedades democráticas}

La base de la discusión que sostiene este artículo es la relación y las tensiones entre los planteamientos de la Ilustración y el posterior ataque que ésta recibió del Romanticismo y en cómo esta tensión, esta dialéctica, se traslada en sucesivas etapas de la historia. Una de estas etapas es la Transición y los primeros años de la democracia española ya consolidada, que supuso la recuperación de la democracia y la libertad tras más de 30 años de dictadura franquista. El Robinson urbano testimonia esas tensiones. Por un lado, la obra celebra la llegada de la libertad y es un canto al progreso; por otro, denuncia sus excesos o sus desvíos y es una 
advertencia sobre la puesta en riesgo del ideal último ilustrado: la emancipación del hombre y la creación de un sistema de libertad real y de justicia social. Precisamente, como se verá, las mismas claves que sustentaron la reacción del Romanticismo a la Ilustración.

Kant define la Ilustración como (2004, p. 33) "el hecho por el cual el hombre sale de la minoría de edad. Él mismo es culpable de ella. La minoría de edad estriba en la incapacidad de servirse del propio entendimiento, sin la dirección de otro [...] iSapere aude! iTen valor de servirte de tu propio entendimiento! He aquí la divisa de la Ilustración". La Ilustración nace en Europa en el siglo XVIII como el gran proyecto modernizador del ser humano. Como advierte Cassirer, ésta no surge de la nada sino que tiene sus antecedentes (1993, p. 17) en "el movimiento literario-espiritual del Renacimiento" del siglo XV, la reforma religiosa del siglo XVI y un siglo más tarde "el triunfo de la filosofía cartesiana [que] cambia por completo toda la imagen del mundo".

El proyecto ilustrado tiene como objetivo primordial la emancipación del ser humano. $Y$ en un escenario de libertad, argumenta Kant, "es posible que el público se ilustre a sí mismo [...] incluso, casi es inevitable".

Ese vínculo entre libertad y razón lleva inexorablemente a la idea de progreso, que tanto define al proyecto ilustrado. De este modo, señala Cassirer $(1993$, p. 18) que "la vida espiritual del siglo [XVIII] [...] se halla presa en un poderoso movimiento que la lleva hacia adelante". Apenas hay, añade (1993, p. 19), siglo alguno "impregnado tan hondamente [...] [y] movido con tanto entusiasmo por la idea del progreso espiritual como el Siglo de las Luces".

Hasta tal punto esto es así que Kant asegura (2004, p. 37) que "la determinación originaria [de la naturaleza humana] consiste, justamente, en ese progresar", es decir, concreta (2004, p. 36), en "ampliar sus conocimientos" y "promover la ilustración".

La palanca del progreso es la razón. "Cuando el siglo XVIII quiere designar esta fuerza [del espíritu que enciende la llama del progreso] apela al sustantivo razón [...] El siglo XVIII está saturado de la creencia de la unidad e invariabilidad de la razón", argumenta Cassirer (1993, p. 20).

Pero apelar a la razón no es sólo una apelación en el vacío; implica un cambio de paradigma completo que, a su vez, lleva a la explosión del positivismo científico que vivirá Occidente a partir de ese momento. Este cambio de giro radical lo expone así Cassirer (1993, p. 21): "La filosofía del XVIII toma como modelo no a Descartes sino a Newton. No una hipótesis inicial a partir de la cual se va deduciendo, paso a paso, un sistema filosófico completo que lo abarca todo"

A partir de ahora, prosigue el filósofo alemán (1993, p. 22), se actúa del siguiente modo: "No en partir de un punto inicial cualquiera, arbitrariamente por supuesto, de una hipótesis, para luego desarrollar por completo las conclusiones implícitas en ella 
[...] Un punto de partida realmente unívoco no nos lo pueden proporcionar la abstracción y la definición física, sino tan sólo la experiencia y la observación".

"Frente a este espíritu de sistema [de la filosofía anterior, propia de Descartes] se proclama ahora una nueva alianza entre el espíritu positivo y el racional', y en este esquema, a la razón "se la hace desplegar poco a poco del conocimiento progresivo de los hechos", dice Cassirer (1993, p. 23).

Este manual de usuario que va a suponer la razón y el positivismo científico se aplicará a todos los campos con ceguera, como si fuera una fórmula mágica infalible. Incluso al as legislaciones, como advierte Kant: "El modo de pensar de un jefe de Estado que favorece esa libertad llega todavía más lejos y comprende que, en lo referente a la legislación, no es peligroso permitir que los súbditos hagan un uso público de la propia razón y expongan públicamente al mundo los pensamientos relativos a una concepción más perfecta de esa legislación. la que puede incluir una franca crítica a la existente" (2004, p. 39).

Ese vínculo entre libertad, razón, progreso y democracia, fue enseguida descrito por el mismo Tocqueville, quien en su La democracia en América dejó escrito que (2017, p. 107) "la idea del progreso y de la posible perfección ilimitada de la especie humana [es] propia de los períodos democráticos".

Sin embargo, como advierten Adorno y Horkheimer, esto tiene sus contrapartidas (1998, p. 59): "La Ilustración, en el más amplio sentido de pensamiento en continuo progreso, ha perseguido desde siempre el objetivo de liberar a los hombres del miedo y constituirlos en señores [...] El programa de la Ilustración era el desencantamiento del mundo. Pretendía disolver los mitos y derrocar la imaginación mediante la ciencia". Derrocar la imaginación: es contra eso, como se verá, contra lo que clamarán los románticos, contra el rodillo opresivo y deshumanizador de la razón positivista, de la razón ilustrada llevada a su paroxismo, como si de una nueva religión se tratase.

La reacción romántica contra la Ilustración es un fenómeno propio y genuino de la Modernidad. El Romanticismo fue el primer cuestionamiento de la Ilustración. Pero no ha sido el único hasta el punto de que ese debate se ha prolongado hasta nuestros días de diversas maneras, como se analizará más tarde. De hecho, como ha afirmado Innerarity (1989, p. 13), "la filosofía contemporánea se ha convertido en una reflexión sobre la Modernidad".

Una obra como El Robinson urbano, tan anclada en los parámetros ilustrados, por una parte, y tan heredera al tiempo de la estética romántica, por otra, ofrece un marco inigualable para el análisis de esta dialéctica Ilustración-Romanticismo, que es, en no poca medida y como se ha defendido, una reflexión sobre la Ilustración y la Modernidad mismas. Un debate, como argumenta Innerarity, presente y fundamental en la filosofía de nuestros días, y como ha advertido Tocqueville propio de la reflexión sobre la idea de progreso inherente a las sociedades y los períodos 
democráticos. No es casual, por lo tanto, que esta reflexión aparezca tan presente en El Robinson urbano, que vio la luz en plena Transición Española.

\subsection{La Transición y la dialéctica entre la Ilustración y el Romanticismo}

Como ha descrito, entre otros, Isaiah Berlin (2000), el Romanticismo es una corriente filosófica y artística que surge en el siglo XVIII como reacción contra la Ilustración. Pero, ¿qué supuso la Ilustración y por qué atacar el proyecto kantiano? Asegura Berlin (2000, p. 44-45) que

el giro particular que le dio la Ilustración [a la tradición racionalista de Europa] consistió en señalar que las respuestas no podían obtenerse por muchos de los medios tradicionales seguidos hasta el momento [...] La respuesta no puede obtenerse por revelación, ya que las diferentes revelaciones de los hombres parecen contradecirse entre sí. No se puede llegar a ella por tradición, ya que puede demostrarse que la tradición es con frecuencia engañosa y falsa. No puede obtenerse por dogma, por la introspección individual de hombres pertenecientes a un grupo privilegiado, ya que demasiados impostores han usurpado dicha función; y así sucesivamente. Hay solamente un modo de descubrir estas respuestas, y es gracias al uso correcto de la razón, deductivamente como en las ciencias de la matemática, inductivamente como en las ciencias de la naturaleza. Éste es el único camino por el que pueden obtenerse respuestas [...] Y no existe razón alguna por la que tales respuestas, que después de todo han producido exitosos resultados en el mundo de la física y la química, no puedan ser igualmente aplicables a aquellos campos, mucho más problemáticos, de la política, la ética y la estética.

El proyecto ilustrado, que funda la Modernidad, es un proyecto de liberación del hombre, de emancipación del individuo y de afirmación del conocimiento objetivo como herramienta para el progreso científico y moral de la humanidad. La propuesta consistía en abandonar la superstición y abrazarse a la razón para crear una sociedad basada en el análisis científico, objetivo, que desembocara en una sociedad solidaria basada en la justicia social y la libertad, puesto que el mundo era una comunidad de seres humanos iguales, forzosamente hermanados, y la naturaleza, la casa, el entorno, que había que domeñar y acomodarlo al ser humano. Con este telón de fondo surge la idea de progreso y con esos mimbres habría de construirse una sociedad nueva y la historia avanzaría hacia un fin donde el ser humano estaría liberado, emancipado.

Por eso, el siglo XVIII es más una centuria de ensayo y de periodismo (surgen los periódicos modernos, de hecho, en gran parte, además, impulsados por los avances técnicos) que de ficciones novelescas y de poesía lírica. En España: Feijoo, Jovellanos, Cadalso, Meléndez Valdés, Larra, Alberto Lista, Blanco White, etcétera. La poesía va a ser de corte moral y educativa (Iriarte, Samaniego).

Pero la ola ilustrada llega al convencimiento absoluto de que "lo que había logrado Newton en el campo de la física podía, con seguridad, aplicarse también al campo de 
la ética y al de la política" (Berlin, 2000, p. 46), y contra esto, justamente, es contra lo que reaccionan con una violencia inusitada los románticos.

La propuesta ilustrada del siglo XVIII, y de los siglos anteriores, continúa Berlin (2000, p. 154), "era que había una naturaleza de las cosas, un rerum natura, una estructura del mundo. Para los románticos esto era absolutamente falso. No podía haber una estructura en el mundo ya que eso nos aprisionaría, nos sofocaría". Esas reglas científicas, objetivas, aplicadas al ser humano y a la sociedad "pueden convertirse en una espantosa carga, en temibles cadenas y tiranías que nos someten a todo tipo de concepciones por las que ya no se inclina ni el presente ni nuestra propia voluntad [...] Cualquier teoría general [...] es una forma funesta de despotismo que afirma poseer una validez objetiva que está por encima de la elección individual", dice Berlin (2000, p. 190).

Acaso por eso, "en Novalis leemos que la naturaleza ha sido 'denigrada a la condición [...] de una máquina uniforme", añade Rüdiger Safranski (2018, p. 175). Este autor (2018, p. 174), de hecho, recuerda que los románticos condenaron "el desencanto del mundo a causa de la racionalización". De este modo, "los ámbitos de la vida y del trabajo se organizan cada vez más según la forma de una 'racionalidad instrumental'. Lo racional y lo instrumental juntos se condenan en lo que Weber llama la jaula de acero de la modernidad".

Safranski, en la línea de Berlin, sostiene (2018, p. 175) que los románticos denunciaban que "el crepúsculo misterioso ha cedido su puesto [a causa de los postulados ilustrados] a una artificial luz del día [...] Esta 'luz gris' de la Ilustración corriente se producía para los románticos no sólo en las cabezas sino también en la realidad social, que ellos experimentaron como un mecanismo cada vez más reglamentado y uniforme".

A la concepción burguesa e ilustrada del arte como utilidad, los románticos le oponen una metafísica del arte (Safranski, 2018, p. 177-178), de manera que si el utilitarismo de la estética ilustrada apelaba a la objetividad y al realismo, el Romanticismo le responde con un arte que se nutre y proclama lo maravilloso, lo prodigioso, lo excéntrico, lo irracional (Safranski, 2018, p. 179), de manera que los románticos sienten pavor y opresión ante la perfección de las formas geométricas (Safranski, 2018, p. 182) cuando un ilustrado habría sentido armonía, estabilidad y paz.

El Romanticismo es una crítica a la deshumanización y la involución moral que la técnica y la ciencia impondrían en el ser humano y la sociedad, una cuestión de enorme trascendencia en estos momentos para la actual sociedad red: digital, globalizada e hiperconectada. Esta cuestión ha sido planteada recurrentemente por los románticos (no sólo en el XVIII, también en el XIX, con Baudelaire en Las flores del mal, en un sentido pesimista, y Victor Hugo con Los miserables, en una vertiente optimista) y la Posmodernidad la volvió a poner en el siglo XX de nuevo sobre la mesa con la experiencia rotunda de Auschwitz: chasta qué punto, el progreso científico, el avance de la ciencia y la técnica, ha traído o puede traer un progreso 
moral, han supuesto o pueden suponer la consecución del hombre nuevo, de la sociedad nueva y perfecta? O qué es una sociedad perfecta y si dejaría lugar esa perfección a la expresión de lo humano. Al fin y al cabo, es volver a plantear en otros términos del viejo dilema entre libertad y orden o, como más a menudo se planeta en la actualidad, libertad y seguridad, la eterna tensión (probablemente irresoluble) entre lo apolíneo y lo dionisíaco, por plantearlo en términos nietzscheanos.

Éste es el eje dialéctico entre la Ilustración y el Romanticismo y es un eje que preña la Posmodernidad misma, concebida como el período que se inicia tras el primer fin de la Modernidad simbolizado, como hemos señalado, en Auschwitz. A pesar de esta trágica experiencia, Antonio Muñoz Molina, lejos de considerar la Modernidad y la Ilustración como proyectos fracasados definitivamente, reivindica sin ambages en El Robinson urbano, su opera prima, la Ilustración, es decir, la razón frente a la superstición y, con ello, el realismo estético, es decir, la narración de la memoria y de lo cotidiano para testimoniar (en un claro vínculo con el ejercicio del periodismo como relato factual, como no-ficción), el realismo de la gran novela clásica del siglo XIX, de Flaubert, Dickens, Eliot, Galdós, Clarín, Tolstoi, Proust y Mann como acaso sus últimos herederos.

En el caso del autor de El jinete polaco, esta reivindicación es más que lógica: la Ilustración, el ideal republicano, el proyecto moderno, había cuajado en España excepcionalmente desde su primer intento con la Constitución liberal de Cádiz de 1812. La Transición española, los años en que Muñoz Molina nace como autor, son la realización de ese ideal ilustrado. El Robinson urbano, enclavado en ese marco histórico, es una defensa de los ideales ilustrados y de la Modernidad, pero también una alerta de sus riesgos y amenazas. Es decir, de nuevo una puesta al día de la dialéctica entre la Ilustración y el Romanticismo, el prisma que se va a aplicar para el estudio de estos artículos.

\section{RESULTADOS}

Fue Kant, en su obra Observaciones sobre el sentimiento de lo bello y lo sublime, de 1764, quien anticipó el sentimiento romántico al abordar la emoción de lo sublime en contraste con la de lo bello. Según observa el filósofo prusiano (2011, p. 4-5):

La emoción en ambos es agradable, pero de muy diferente manera. La vista de una montaña cuyas cimas nevadas se alzan sobre las nubes, la descripción de una furiosa tempestad [...] producen agrado, pero unido a terror; en cambio, la contemplación de prados floridos, valles con arroyos ondulantes, cubiertos de rebaños pastando; la descripción del Elíseo o la pintura que hace Homero del cinturón de Venus provocan igualmente una sensación agradable, pero alegre y sonriente [...] La noche es sublime, el día es bello [...] Lo sublime es, a su vez, de distinta naturaleza. El sentimiento que lo acompaña es a veces de cierto horror o melancolía.

Esa dialéctica bello-sublime será también propia de la etapa romántica como respuesta, sobre todo, a la aniquilación de lo misterioso en el mundo natural por parte del desarrollo científico-técnico. En términos generales, la Ilustración propugna 
lo bello, el día; el Romanticismo lo sublime, la noche. Lo racional, lo diáfano, lo rectilíneo, es bello; lo mágico, lo irracional, lo misterioso, lo curvo, es sublime. De nuevo, lo apolíneo y lo dionisíaco.

Frente al fanatismo y las amenazas de la razón y del positivismo ciego, los románticos, afirma Berlin (2000, p. 33-34), promovieron "un gran retorno al emocionalismo, que [hizo surgir] un repentino interés por lo primitivo y por lo remoto - por lo remoto en el tiempo y en el espacio-, que se manifestó un anhelo por lo infinito". Y ahí surge la nostalgia y la paranoia. La primera, explica Berlin (2000, p. 142), "se funda en el hecho de que intentamos comprender lo infinito, pero éste es inabarcable, razón por la que nada de lo que hagamos nos dará satisfacción". En cuanto a la segunda, la paranoia, está vinculada a lo infinito, sobre todo de la historia y de la conciencia del yo. Asegura Berlin (2000, p. 145):

Hay algo detrás, en las oscuras profundidades del inconsciente o de la historia; hay algo, de todos modos, que nosotros no podemos alcanzar y que frustra nuestros más caros deseos. A veces se lo concibe como cierta naturaleza hostil e indiferente; otras veces, como las lecciones de la historia [...] Esta paranoia se manifiesta de múltiples maneras, unas más crueles que otras. Se pone de manifiesto, por ejemplo, en la búsqueda de todo tipo de conspiraciones en la historia. Los hombres comienzan a sospechar que tal vez la historia esté movida por fuerzas sobre las que no tienen control [...] Prácticamente, lo concibe como una especie de enorme e irónica fuerza aristofánica que se burla de los pobres seres humanos, quienes intentan construir sus pequeños hogares en la ladera de lo que ellos entienden que es una verde y florida montaña, pero que en realidad es el gran volcán de la historia humana.

Para empezar, esta idea del infinito está presente de forma palmaria y central en El Robinson urbano de diferentes maneras, especialmente, en cuanto a los personajes y el escenario donde se desarrolla la acción. Por un lado, Robinson y Apolodoro son personajes eternos, van viajando a través del tiempo desde tiempos inmemoriales de manera que El Robinson urbano describe sus andanzas en la Granada de la Transición (que es también, acaso por eso, la Granada mítica de la Alhambra) pero desaparecerán y se irán a otra ciudad donde volverán a emprender otras aventuras futuras y atemporales.

Está también la ciudad, la Granada-mito, eterna, por lo tanto, la Granada en la que "hay que buscar siempre la distancia más curva entre dos puntos" ("El extranjero de sí mismo"). Como referentes inmediatos, es la ciudad-laberinto de Borges, es el Spleen de París de Baudelaire (referencia absoluta de esta obra de Muñoz Molina) y la ciudad odiséica de Leopold Bloom en el Ulises de Joyce, citado ya como referencia desde el artículo inaugural de esta serie ("Primer manual"):

"Tuvo que venir Joyce [...] para dar forma definitiva al laberinto y al perfil del robinsón urbano. Ulises, primer náufrago y peregrino del que tenemos memoria, no busca ya su Ítaca imposible en las islas del Mediterráneo despojadas de todo misterio o aventura por los cruceros turísticos- sino en las calles tristes de Dublín. Ulises se hurga la nariz mientras mira los 
escaparates de las tiendas. Ulises apenas hace nada: sólo mira, camina, murmura, saluda a algún conocido, pura mirada sin voluntad ni propósito".

Se observa en esta cita, por un lado, una clara reacción de inspiración romántica en la queja de la pérdida del misterio del Mediterráneo por los cruceros turísticos, un asunto que será recurrente a lo largo de estos artículos y que está contrarrestado continuamente por una llamada al viaje y la aventura urbana, precisamente dos elementos también claramente románticos, como sostiene Safranski (2018, p. 193), que alude incluso a "los grandes extravíos". Muñoz Molina, sin ir más lejos, apela a "esa ardua peregrinación que muy probablemente no termine nunca" ("Juego de las conmemoraciones"). Por otra parte, está expresado como un mandamiento diáfano el pilar estético y ético de El Robinson: un robinsón, el Ulises moderno, es, escribe Muñoz Molina, "pura mirada".

De nuevo, una figura que hiende sus raíces en el Romanticismo, a saber: el mirón romántico (Safranski, 2018, p. 201) como personaje clave de la ciudad romántica y odiséica, en este caso la Granada de la Transición, la Granada ambivalente que entrecruza en dos planos simultáneos la ciudad mítica y la urbe presente y luminosa de la democracia recuperada, donde "la gente escribe y pinta, hace música, imagina periódicos y empieza a usar la libertad", como se dice en "Septiembre escueto y rosa".

La ciudad-laberinto es un ataque a lo rectilíneo de la Ilustración. Los románticos, desmenuza Safranski (2018, p. 182), critican que "lo recto y medido, aunque exteriormente sea espacioso, tiene el efecto paradójico de provocar un sentimiento de estrechez" de manera que, prosigue este autor (2018, p. 182)

se ensalzan "las 'oscilaciones infinitas' de la vida. Lo intrincado, también lo oscuro, atrae, con tal de que permita digresiones y divagaciones, con tal de que esté dispuesto a las sorpresas y permita una 'excitante confusión'. Por esta misma razón se ensalza la laberíntica ciudad medieval y se prefieren los jardines naturales al acompasado parque francés.

Ya en "Primer manual", como se ha visto, se habla de la ciudad como "laberinto urbano" y de la nueva aventura urbana: "el placer, absolutamente inédito hasta entonces de recorrer la ciudad sin ir a parte alguna y sin tener otra compañía que la propia voz en la conciencia". Por esto mismo, se denuncia en dicho artículo que "si uno se pasea tranquilamente y sin objeto por algunas ciudades americanas es sospechoso para la policía". Esto es otro ejemplo de la dialéctica IlustraciónRomanticismo en tanto recupera una de las críticas románticas a la Ilustración: el mito del control humano, que en la actualidad sería la denuncia del gran hermano en que se están convirtiendo las ciudades modernas (debido a las tecnologías digitales y los avances informáticos), a pesar de que fueron hechas para la emancipación: "El aire de la ciudad [nos] hace libres, decía un refrán medieval", escribe Muñoz Molina en ese "Primer manual".

Esta ciudad laberíntica apela a lo eterno de la aventura de pasear por ella, por sus calles, el mejor método de descubrirla: dejarse llevar sin rumbo. Es decir, el 
personaje de Robinson en contraposición a Apolodoro, que es el personaje del recogimiento, de la habitación, del pensamiento (Ilustración) frente a la acción y la aventura (Romanticismo) que representa Robinson. Aunque el acto de mirar, la observación contemplativa sea de herencia claramente ilustrada (Berlin, 2000, p. 123).

Pero Robinson es también el flâneur descrito por Walter Benjamin como el habitante anónimo de la ciudad moderna, que la conoce con la mirada y caminando por ella, haciendo con el paseo su propia aventura, una aventura que se asemeja a la de escribir: "La ciudad revive en este septiembre tibio y prometedor como un papel en blanco" ("Septiembre escueto y rosa"). De este modo, pasear, ver y escribir es una misma cosa: es el conocimiento mediante la acción y la observación.

Como escribe Benjamin (2005, p. 447): "Máxima del flâneur. en nuestro mundo uniformizado, hay que ir sobre el terreno y a fondo; el extrañamiento y la sorpresa, el exotismo más sorprendente, están muy cerca", de manera, asegura que la ciudad aparece como "la realización del viejo sueño humano del laberinto. A esa realidad, sin saberlo se consagra el flâneur". (2005, p. 434).

La caminata y la mirada apelan a ese yo romántico y moderno, expresión de la subjetividad libre e irracional frente a la opresión de una geometría objetiva de inspiración ilustrada (en la versión pesimista de la Ilustración), es el yo que pasea sin rumbo por la ciudad y la descubre mirándola, es el voyeur, el espía: "Robinson espía: mil ojos abiertos quisiera tener para recibir de un solo golpe todas las cosas que la ciudad le ofrece", escribe Muñoz Molina en "Primer manual".

Esa mirada lleva a la escritura, y la escritura lleva al café, al refugio del Robinson, un refugio no apartado (como el apartamento misterioso y casi monástico de Apolodoro) sino enclavado en el corazón mismo de la ciudad. El café es El Suizo en El Robinson urbano, donde Robinson y Apolodoro se encuentran a menudo, y ese café es el lugar donde se produce el nacimiento de la literatura y el periodismo modernos, como ha expuesto Martí Monterde (2007, p. 273):

El café es el gabinete de trabajo del escritor [...] a lo largo del siglo XIX, pero el siglo XX añade el carácter de refugio del cual la ventana sería garante y mirador al mismo tiempo. El regreso al café del flâneur fue desasosegado, y el cristal, transparente pero sólido, será la distancia última, la imprescindible distancia que el individuo podrá mantener para evitar su disolución en la nada del todo.

De nuevo, esa literatura moderna que reivindica Muñoz Molina en "Primer manual": una literatura "moderna, asida del instante, cuyo espacio natural eran las páginas apresuradas de los periódicos", escribe el autor de Úbeda. El café, el bar, El Suizo, en la granada robinsoniana, es el enlace entre la ciudad y el escritor, el periodista, el cronista, como dice Muñoz Molina, y ese enlace se realiza a través de un vínculo claro: la ventana. De nuevo, otro elemento romántico, como apunta Safranski (2018, p. 192), esa atadura (que conecta con la melancolía y la aventura) a la realidad 
se muestra en la preferencia por el motivo de la ventana [...] el que añora mira desde la ventana y oye las canciones de los caminantes sobre los viajes que conducen a una lejanía [...] Las ventanas abren la mirada a ventanas abiertas, a imágenes que llevan a lo imprevisible [...] [y se] llama a ponerse en marcha.

Los habitantes del café (diurno) o del bar (nocturno), "miran a la calle como peces inmóviles tras el cristal del acuario, porque en esos bares [...] los tubos de neón y las paredes pintadas de un verde funeral dan al aire una tristeza acuática", escribe Muñoz Molina ("El vino de los héroes").

La contemplación de la realidad infinita que jamás se llega a abarcar con la mirada fue para los románticos (Safranski, 2018, p. 193) una invitación al viaje (así, "Invitación al viaje", se titula, precisamente, uno de los artículos de la serie robinsoniana), puesto que anuncia un misterio y unas aventuras que hay que perseguir. Escribe Safranski (2018, p. 193): "[Se trata del] motivo tradicional de los grandes viajes y extravíos, que comienza con Odiseo y la leyenda de los argonautas, y llega a la edad moderna a través de las historias de locos en la Edad Media y del holandés errante. De ellos extraen los románticos el viaje sin llegada ni meta, el viaje $\sin$ fin".

El errante, que a veces es también en las páginas de El Robinson urbano el loco, el chiflado, los sonámbulos urbanos, apela no tanto ya al paseante, al flâneur como a la figura del excluido, del bárbaro (como se dice irónicamente en "La feria de los bárbaros"), del clochard, del mendigo, según la dialéctica (flâneur-clochard) establecida por Benjamin en su análisis de la ciudad moderna, que es laberíntica y urbanamente erótica, pero también industrial y desmitificadora. Hay decenas de referencias al clochard en El Robinson urbano, como en los artículos "Capital de la locura", "El vino de los héroes" o en el mismo "Primer manual", en el que se describe al "hombre la multitud, el haragán, el loco, el músico ambulante, el niño que toca la trompeta [...] el ciego que grita [...] el cómico de la lengua pintado de payaso y el hirsuto mormón".

Pero, volviendo al concepto del viaje, Robinson es, no en vano, descrito como un "perpetuo holandés errante" ("Septiembre escueto y rosa") que cuando pisa las calles de Granada, ésta "revive, en este septiembre tibio y prometedor, como un papel en blanco". Robinson siempre está "dispuesto a perderse en un paseo por el wild side, por el lado salvaje o peligroso que tantos frutos promete" ("Breviario de impostores").

El viaje, la aventura, es el antídoto para huir del aburrimiento, algo que entronca también con el corazón mismo de los románticos. Éstos veían en el espacio y el tiempo geometrizados [como] el espectro de una mala Ilustración" (Safranski, 2018, p. 182). De manera que "el malestar por la normalidad [de una vida perfecta y objetivamente organizada] se concentra en el miedo al aburrimiento" (Safranski, 2018 , p. 182). Con los románticos, asegura Safranski (2018, p. 183) "el aburrimiento aparece como el gran tema de la Modernidad [...] Este 'hastío' puede crear hasta el 'horror', que Kant llama horror vacur'. 
El Robinson urbano es prácticamente un ensayo sobre este tema y, no en vano, la obra tiene como modelo y referencia clave Baudelaire y su Spleen de Paris. Por eso, escribe Muñoz Molina ("Septiembre escueto y rosa") que en "los cafés y en las plazas [...] hay el indicio estimulante de una aventura cuyos primeros signos están configurando la imagen de la una nueva ciudad que lentamente vuelve a abrirse", y contrapone esto a los "fogonazos de guerrilla en la espesura del tedio" y llama a liberarse de los "no menos lúgubres designios de los boletines oficiales".

El tedio, por lo tanto, aparece en El Robinson urbano como consecuencia, por un lado, de la opresión de la ciudad moderna (fracaso, por tanto, del proyecto de liberación ilustrado), reflejado especialmente en la organización del trabajo capitalista, que implica un trabajo que no humaniza y que no deja tiempo a la realización personal (en la línea expuesta, entre otros, por Richard Sennett, 2006). Por otra parte, como consecuencia del tedio ante la mecanización de la ciudad, ésta aparece ya como desmitificada y sin magia; ha perdido su aura porque está organizada sin encanto, como una fábrica, como un mecanismo técnico.

Por eso, los Robinsones, se lee en "Primer manual", "esos locos que andan por Granada ensimismados en su peregrinación, están mal vistos por la autoridad". La ciudad moderna que prometía ser fábrica de hombres libres ha acabado siendo un lugar de deshumanización y alienación, de ahí que Muñoz Molina escriba que, al final, "el héroe amargo de la ciudad [es aquel a quien lo asalta] la venida de la noche recostado en el sillón de una oficina sórdida" ("Manhattan Transfer"). Y cuando acaba la noche, como momento de aventura y liberación de las cadenas del día, el robinsón urbano "dócilmente se arranca el antifaz ante el espejo y luego se cepilla los dientes y pone en hora el despertador que habrá de regresarlo al tedio de las simulaciones aceptadas. Así se rinde Robinson una y otra noche" ("Breviario de impostores").

La alienación urbana se produce, como decimos, en un espacio concreto en el que alcanza su correlato: la ciudad sin aura, sin encanto, de una geometría técnica que no deja espacio a lo humano, que aplasta el ser y su realización: "Cuando se ha nacido para la noche y para la ciudad, toda pared dibuja la forma de una celda y todo horario es una pesadilla de relojes que irrumpen al amanecer en medio de los sueños" ("La trampa en el espejo"). Ante esta situación opresiva, "a ver quién puede o sabe, quién se atreve a borrarse de la frente el número de su carnet de identidad" ("Breviario de impostores"), en una denuncia clara del gran hermano de la ciudad moderna, de absoluta actualidad en estos momentos.

Ante esto, Muñoz Molina reivindica con la escritura una ciudad que aparece como un escenario de aventuras, a menudo marítimas: "Cada acera se convierte inesperadamente para Robinson en la playa del país de los Feacios" ("Vindicación de la rodilla femenina"). "Granada es una gran Alejandría que a todos nos acoge en la había de sus plazas", está escrito en "Primer manual". "El Suizo, como el paseo del salón, es una isla" ("Elogio de El Suizo"). En "Un busto en el salón", se afirma que "los robinsones granadinos necesitan de vez en cuando arribar a alguna isla en forma 
de jardín público". O, en "Los niños terribles", se plantea la doble dualidad de Granada: "Ciudad o selva".

Hay, con todo, una defensa a ultranza en El Robinson urbano de los valores originales y genuinos de la Ilustración como defensa de la razón y como proyecto liberador del ser humano y en aras de lograr una sociedad justa. Por eso, a pesar de la reivindicación de la noche como espacio de libertad, de misterio romántico, de aventuras y de expresión del yo verdadero frente a los meros dígitos de un carnet de identidad, se celebra que "hay hombres nacidos para el día" ("La trampa en el espejo"), y en "Las mañanas, el centro, la serenidad", lo que empieza con un ataque a la moral utilitaria (que ha convertido al ciudadano libre en esclavo de la producción, sin tiempo libre para realizarse, en una ciudad que se ha convertido en una fábrica) acaba siendo un canto a la luz, a la razón, a la mesura y al sosiego de las mañanas como espacio de libertad, de serenidad y de arraigo, frente a la exaltación de la noche sublime, defendida más como juego, por lo tanto:

A las nueve de la mañana, con las manos en los bolsillos o la mirada atenta, practico el minoritario placer de no ir a ninguna parte [...] Se trata de no hacer nada, de obedecer los pasos señalados por el azar y la trama de las calles, de rendirse a un olor a hierba húmeda sorprendido al cruzar unos jardines [...] [Robinson] se pierde en el laberinto de las columnas blancas iluminadas en su cima por una luz como de otro mundo, y cuando vuelve a la calle la claridad del día lo deslumbra, invitándolo a proseguir su oficio peregrino [...] A las nueve de la mañana, el ejercicio de la pereza adquiere el mérito de un acto positivo, de una privada rebeldía [...] Y así, igual que existen desayunos de trabajo, hay que inventar desayunos de placer y concertar las citas amorosas no en los atardeceres, tan desprestigiados por la literatura y las postales, sino en la primera y más dulce hora del día, de tal modo que madrugar no sea un castigo sino una obligación de la felicidad [...] La literatura, que ha exaltado desde siempre los prestigios de la noche, sólo muy raramente se ha ocupado de los modestos goces que deparan las mañanas [...] [Ya escribió Borges que] "en aquel tiempo buscaba los atardeceres, los arrabales, la desdicha, ahora busco las mañanas, el centro y la serenidad".

Aparece reivindicada la luz de la Ilustración frente a la noche romántica, que es, en El Robinson urbano, la luz de la democracia frente a la larga noche de la dictadura franquista. Es "la noche cobarde de las tiranías feroces", como se describe en "Escrito en las paredes"; la noche donde a pesar de todo, prosigue dicho artículo, hay gente que se toma "por su propia mano la libertad de decir lo que no puede ser callado sabiendo que es probable que dos esposas o un disparo dejen roto el grito que estaban escribiendo".

La noche, de este modo, no es ya el escenario romántico de aventuras y transformación, sino la amenaza del día, el mal, la culpa, como la que alberga la ciudad por el crimen de Lorca, como se describe en "El ángel exterminador", donde se habla del espíritu del insigne poeta granadino, precisamente, no como una luz que se inclina sobre Granada sino como una sombra que "vuelve y aparece una y otra vez". 
Frente a esa noche y esas sombras, la luz de la democracia que hacen una ciudad habitable y respirable. "Nos queda el día, por fortuna", dice, no en vano, Muñoz Molina en "Primer manual" porque no sólo el aire de la ciudad hace hombres libres, como se dice en este artículo, sino también su luz, que es la luz de la democracia y de la ciudad libre. Claro que con la llegada de la democracia como realización de los valores ilustrados no se consuma felizmente el final de la historia.

Por este motivo, Muñoz Molina alerta también de las veleidades y del regreso a la superstición y al folklorismo; éste, en parte, llevado por un cierto nacionalismo del terruño, tan vinculado a un mal entendido Romanticismo (Safranski, 2018, p. 165166). Sobre el regreso al folklorismo, hay diversos ejemplos rotundos. En "Granada contra Graná o qué hizo Hegel por Málaga", Muñoz Molina contrapone a la Granada "que en el espacio de unos siglos ha dado a la imaginación del mundo paisajes y nombres memorables", esa otra ciudad, Graná, descrita como

el predio provinciano (no paraíso cerrado sino asfixiante invernadero) donde toda mediocridad tiene su asiento en el Parnaso de las esencias vernáculas y se rinde al culto cultural y espeso a la jayuya, las papas a lo pobre y el chisterazo de a Toma como signos sagrados de lo que antes se llamaba peculiar idiosincrasia y hoy recibe el nombre, ya litúrgico, de señas de identidad.

A esta descripción le sigue la crítica, dirigida además la izquierda, que debería representar la razón y la cultura universal, ilustrada, de que "toda la antigua chacinería localista [...] regresa, momia rediviva, para encarnarse en un potaje de raíces y antiguallas que una cierta izquierda cultural nos suministra como sopa boba para remediar tantos años de indigencia". Es la crítica, como está escrito en dicho artículo, a los "nacionalistas de babucha" y los vanos y alquimistas intentos de "recuperar las cenizas dispersas del Ser Andaluz", hasta el punto de que "nacer en Andalucía no es ya una casualidad ni una desgracia, sino un raro privilegio metafísico".

Muñoz Molina desbroza en dicho artículo las dos claves de su ética y su estética literaria: "en toda ciudad y está cifrado el universo", por lo que en el microcosmos local está también lo universal, pero no en la hinchazón folklórica de los rasgos costumbristas locales; por otra parte, está escrito en este artículo, "nadie tiene la obligación de ser profeta en su tierra pero un artista ha de ser siempre peregrino en su tierra".

Esta crítica se añade a ciertos síntomas que el autor detecta del fracaso de los ideales ilustrados. Es en ese sentido cuando advierte del "santo regocijo de lo irracional y milagroso" (en "Razón de amor") o del fanatismo del fútbol como pseudorreligión (en "Instrucciones para sobrevivir a los mundiales").

Frente a esto, está la defensa rotunda de la razón y, como obra de la razón, la ciudad moderna que hace hombres libres y humaniza. "Cualquier breve victoria de la razón se convierte en un acontecimiento milagroso", escribe en "Elogio de El Suizo". 
Por este motivo, hay en este artículo una crítica feroz la destrucción del patrimonio como mutilación de la memoria (una ciudad es "la dilatada memoria de sí misma", se dice) y se carga contra "los héroes de la piqueta". De ahí que en "Las mañanas, el centro, la serenidad" se celebre que "cuando se cierran calles al tráfico para imponer en ellas la olvidada delicia de caminar tranquilamente", y en "Un busto para el salón" se alabe que "con la Transición [...] no sólo han cambiado, aunque muy despacio algunos uniformes, sino que la moda municipal ha vuelto a deslizarse hacia lo verde".

Después de tantos años grises y oscuros, llega el verde y la luz de la Transición, inserta, como la democracia española misma, en las tensiones, los excesos y los aciertos de los planteamientos del Romanticismo y de la Ilustración.

\section{CONCLUSIONES}

Los artículos periodísticos de El Robinson urbano suponen el bautismo literario y periodístico de Antonio Muñoz Molina. Aparecieron en el periódico local Diario de Granada en 1982 y 1983; un libro que recogía una selección de los mismos fue editado por el propio autor un año después. El Robinson urbano, por lo tanto, ofrece la base para el estudio de los rasgos fundamentales de la obra primigenia de quien se convertiría en una de las voces fundamentales de la literatura en lengua castellana contemporánea.

La dialéctica entre la Ilustración y el Romanticismo ofrece un prisma singular para el análisis de estos artículos periodísticos. En primer lugar, por el propio contexto histórico concreto, la Granada de la Transición democrática y de la libertad recuperada tras las décadas de dictadura franquista.

En segundo lugar, por el marco histórico más amplio de Occidente, la Posmodernidad (tras Auschwitz como símbolo absoluto del primer fracaso de la Modernidad, justo como advertía la crítica romántica a la Ilustración).

En tercer lugar, por la propia tradición literaria y periodística declarada explícitamente por el autor en estos textos, su bautismo para las Letras: la modernidad y el spleen de Baudelaire, el Ulises deambulante de Joyce, los paraísos artificiales de De Quincey, el romanticismo periodístico y de testimonio de Larra, la ciudad-laberinto de Borges.

Pero también por los temas (de inspiración romántica, como se ha analizado siguiendo a Berlin y Safranski) que aborda Muñoz Molina en estos artículos: la aventura urbana (Verne, la literatura romántica de viajes, etc.), hacer poesía de la realidad, alabar la ciudad moderna como fábrica de libertad pero también alertar de la opresión que una ciudad puede ejercer (si se convierte en una fábrica, en una jaula de oro: aniquilación del yo, alienación), el misterio de la noche, la noche como liberación, la alabanza de la luz de la razón y la emancipación del yo frente a la noche de la dictadura y la superstición, pero también el terror que late tras la normalidad de la luz geométrica del día, los arquetipos del flâneury el clochard como personajes centrales de la ciudad moderna (Benjamin), la crítica a los folklorismos 
del terruño y de postal frente a la vindicación del artista del microcosmos anclado en su comunidad íntima, la Literatura del yo romántico y su vínculo con el articulismo y, por lo tanto, con el periodismo moderno. Ambas esferas, la literatura y el periodismo modernos, hacen, además, su aparición en el siglo XVIII y XIX en un escenario común: el café (Martí Monterde).

El café, como refugio del escritor en el corazón mismo de la ciudad, aboga por la mirada y ésta llama a la acción: a la escritura y al viaje (la aventura urbana). Se llama a así al ejercicio de una literatura de la realidad anclada en el instante, en el ahora, que, como escribe Muñoz Molina en El Robinson urbano, encuentra su soporte ideal en las páginas apresuradas de los periódicos. Uno de los objetivos de esa escritura es contar la ciudad, lo cotidiano, para recomponer la fragmentación de la ciudad y del individuo urbano y tejer un hilo conductor, un relato, una narración unificadora. Y escribirlo para que conste, para registrarlo todo ahora que la ciudad, el mundo y sus habitantes se mueven más rápido que nunca.

Ese ejercicio de recomponer también se vincula con la memoria. Una ciudad, escribe Muñoz Molina en estos artículos, es la "memoria dilatada de sí misma". Ese regreso al pasado también es de inspiración romántica; una incorrecta interpretación de ello fue lo que acabó derivando en un casposo folklorismo romántico (Safranski, 2018 , p. 328) y fabrica eso que Vattimo (1990, p. 123) llama el mito del origen (frente al mito del progreso) que, a la postre, ha sido la base de muchos nacionalismos posmodernos, como versión de un romanticismo político, tan criticado por autores como Safranski $(2018$, p. 324, 325, 353) y por el propio Muñoz Molina, como se ha descrito.

Tanto la literatura de la realidad como la literatura de la memoria son los ejes por los que transita toda la obra posterior del escritor de Úbeda, cuyos últimos títulos, de hecho, vuelven directamente a la raíz establecida en los artículos de El Robinson urbano: Sefarad (2001), El viento de la luna (2006), Como la sombra que se va (2014), Un andar solitario entre la gente (2018). A la rama de la literatura de la memoria pertenecerían prácticamente el resto de sus obras pero muy especialmente Beatus Ille (1986), El jinete polaco (1991) y La noche de los tiempos (2009).

Como sugerencia para futuras investigaciones quedaría analizar la obra de Muñoz Molina bajo el prisma de la dialéctica entre la Ilustración y el Romanticismo. Sirva este artículo como primera modesta piedra que haga de base inicial de esta posible línea de investigación.

\section{Bibliografía}

Adorno, T. W., Horkheimer, M. (1998). Dialéctica de la Ilustración. Ed (3ra). Madrid. Editorial Trotta.

Benjamin, W. (2003). La obra de arte en la época de su reproductibilidad técnica. México. Ítaca. 
Benjamin, W. (2005). Libro de los pasajes. Madrid. Akal.

Berlin, I. (2000). Las raíces del Romanticismo. Madrid. Taurus.

Casals Carro, M. J. y Santamaría Suárez, L. (2000). La opinión periodística. Argumentos y géneros para la persuasión. Madrid. Fragua.

Cassirer, E. (1993). Filosofía de la ilustración. Fondo de Cultura Económica. Ed (3ra), cuarta reimpresión. Madrid.

De Tocqueville, A. (2017). La democracia en América. Tercera edición. Madrid. Alianza.

Grohmann, A. (2005). La escritura impertinente. Número doble 703 y 704. Ínsula. Madrid.

Innerarity, D. (1989). Dialéctica de la modernidad. Madrid. Ediciones Rialp.

Kant, I. (2004). Filosofía de la historia. Qué es la Ilustración. Argentina. Terramar ediciones.

Kant, I. (2011). Observaciones sobre el sentimiento de lo bello y lo sublime. México. Fondo de Cultura Económica.

Lyotard, J.-F. (1996). La posmodernidad explicada a los niños. Barcelona. Gedisa.

Magris, Cl. (2001). Utopía y desencanto. Historias, esperanzas e ilusiones de la modernidad. Barcelona. Anagrama.

Mainer, J. C. (2009). Antonio Muñoz Molina o la posesión de la memoria. En ANDRÉS-SUÁREZ, Irene y CASAS, Ana (ed.) (2009): Antonio Muñoz Molina.

Muñoz Molina, A. (1996). La huerta del edén. Madrid. Ollero y Ramos.

Muñoz Molina, A. (1997). El Robinson urbano. Barcelona. Seix Barral.

Muñoz Molina, A. (2002). La vida por delante. Madrid. Alfaguara.

Muñoz Molina, A. (2004). Ventanas de Manhattan. Barcelona. Seix Barral.

Muñoz Molina, A. (2011). Azares del oficio. El País, 17/IX/2011. https://elpais.com/diario/2011/09/17/babelia/1316218342 850215.html

Muñoz Molina, A. (1982). Breviario de impostores. 25 de junio de 1982, Diario de Granada. 
Muñoz Molina, A. (1982). Capital de la locura. 10 de septiembre de 1982. Diario de Granada.

Muñoz Molina, A. (1983). De los augurios. 7 de enero de 1983. Diario de Granada.

Muñoz Molina, A. (1983). El ángel exterminador. 21 de enero de 1983. Diario de Granada.

Muñoz Molina, A. (1982). El extranjero de sí mismo. 10 de diciembre de 1982. Diario de Granada.

Muñoz Molina, A. (1982). El vino de los héroes. 12 de noviembre de 1982. Diario de Granada.

Muñoz Molina, A. (1982). Elogio de El Suizo. 27 de agosto de 1982. Diario de Granada.

Muñoz Molina, A. (1982). Escrito en las paredes. 28 de enero de 1983. Diario de Granada.

Muñoz Molina, A. (1982) Granada contra Graná o qué hizo Hegel por Málaga. 1 de octubre de 1982. Diario de Granada.

Muñoz Molina, A. (1982). Instrucciones para sobrevivir a los mundiales. 18 de junio de 1982. Diario de Granada.

Muñoz Molina, A. (1982) Invitación al viaje. 3 de septiembre de 1982. Diario de Granada.

Muñoz Molina, A. (1982) Juego de las conmemoraciones. 4 de junio de 1982. Diario de Granada.

Muñoz Molina, A. (1983) La estación florida. 18 de marzo de 1983. Diario de Granada.

Muñoz Molina, A. (1982) La feria de los bárbaros. 11 de junio de 1982. Diario de Granada.

Muñoz Molina, A. (1982) La trampa en el espejo. 19 de noviembre de 1982. Diario de Granada.

Muñoz Molina, A. (1982) Las mañanas, el centro, la serenidad. 20 de agosto de 1982. Diario de Granada.

Muñoz Molina, A. (1982) Los crímenes del museo de cera. 26 de noviembre de 1982. Diario de Granada. 
Muñoz Molina, A. (1982) Los niños terribles. 24 de septiembre de 1982. Diario de Granada.

Muñoz Molina, A. (1983) Manhattan Transfer. 14 de enero de 1983. Diario de Granada.

Muñoz Molina, A. (1982) Primer manual. 7 de mayo de 1982. Diario de Granada.

Muñoz Molina, A. (1982) Razón de amor. 10 de agosto de 1982, Diario de Granada.

Muñoz Molina, A. (1982) Septiembre escueto y rosa. 17 de septiembre de 1982. Diario de Granada.

Muñoz Molina, A. (1982) Un busto para el Salón. 22 de mayo de 1982. Diario de Granada.

Muñoz Molina, A. (1983) Viajero en la honda noche, 25 de febrero de 1983. Diario de Granada.

Muñoz Molina, A. (1982) Vindicación de la rodilla femenina. 14 de mayo de 1982. Diario de Granada.

Ruiz Rico, M. (2011). El Robinson en Nueva York. Sevilla. Centro Andaluz del Libro.

Ruiz Rico, M. (2012). El Robinson urbano. Soporte periodístico y literario en la obra de Antonio Muñoz Molina. Universidad de Sevilla. https://idus.us.es/xmlui/handle/11441/24398

Ruiz Rico, M. (2013). El Robinson urbano. Sevilla. Ámbitos.

Safranski, R. (2018). Romanticismo. Una odisea del espíritu alemán. Barcelona. Tusquets.

Sennett, R. (2006). La corrosión del carácter. Las consecuencias personales del trabajo en el nuevo capitalismo. Barcelona. Anagrama.

Seoane, M. C. (2008). Columnistas que aún no se llamaban así. León Gross, Teodoro Adolfo (coord.) y Gómez Calderón, Bernardo (ed.) (2008). El artículo literario: Manuel Alcántara. Málaga. Universidad de Málaga.

Soria Olmedo, A. (1998). Una indagación incesante. Madrid. Alfaguara.

Vattimo, G. (1990). La sociedad transparente. Barcelona. Paidós.

\section{AUTOR:}

Revista de Comunicación de la SEECI. 2021, nº 54, 55-78 
Ruiz Rico, M. Dialéctica Ilustración y Romanticismo en los artículos periodísticos de El Robinson urbano, de Antonio Muñoz Molina

\section{Manuel Ruiz Rico}

Doctor en Periodismo por la Universidad de Sevilla. Corresponsal de Público en Estados Unidos.

manuel.ruiz@democmedia.com

Orcid ID: https://orcid.org/0000-0002-8540-3866 